\title{
Cognição, emoção e reflexão na sala de aula: por uma abordagem sistêmica do ensino/aprendizagem de inglês
}

Rodrigo Aragão

Programa de Pós-Graduação em Estudos Lingüísticos

Universidade Federal de Minas Gerais

Este artigo propõe articular a Biologia do Conhecer de Humberto Maturana (1998) à pesquisa narrativa de Jean Clandinin e Michael Connelly (2000), de modo a propor uma abordagem sistêmica para a pesquisa sobre o ensino e a aprendizagem de inglês e superar a dicotomia teoria-prática que domina comumente a reflexão no campo. Para tanto, apresento o estudo de uma narrativa em contexto de sala de aula de inglês que irá lançar luzes sobre a natureza histórica das relações operacionais entre emoção e cognição. Defendo que as emoções e a história de vida da participante da pesquisa especificam suas ações na sala de aula. Argumento que a construção de narrativas propicia a emergência de uma atitude reflexiva que possibilita transformações nas emoções e ações na conduta de sala de aula. Com isso, pretendo contribuir para a expansão de nossos horizontes reflexivos sobre a inter-relação entre linguagem, cognição e emoção, fundamental para nossa compreensão da sala de aula.

This paper aims at articulating the epistemological framework of Biology of Cognition (MATURANA, 1998) and Narrative Inquiry (CLANDININ \& CONNELLY, 2000) in order to propose a systemic approach for the teaching and learning of English as a Foreign Language and to overcome the theorypractice dichotomy that usually dominates the field. For this reason, I present a study of a narrative in the context of an English language classroom that will shed light on the historical nature of the operational interfaces between emotion and cognition. I claim that the research participant's emotions and life history determine her classroom actions. I argue that the construction of narratives foster the emergence of a reflective attitude that can bring forth transformations in emotions and actions in the classroom. Wtih this I have the objective to contribute to the expansion of our reflective horizons about the inter-relationship of language, cognition and emotion, which are fundamental to our understanding of the classroom. 


\section{O desejo por reflexões epistemológicas na Lingüística Aplicada}

Na virada do milênio, assistimos a uma explosão de artigos, mesas-redondas e debates que revisitaram o campo da Lingüística Aplicada, repensando sua história teórico-metodológica e seus horizontes epistemológicos. É visível o sentimento de renovação para o qual acenam pesquisadores renomados do campo, e é amplo o reconhecimento de que a Lingüística Aplicada está, de fato, fazendo com que sua disciplina mãe, a Lingüística, repense alguns de seus conceitos fundadores (RAJAGOPALAN, 2003, p. 77-81). É nesse contexto que se insere este artigo, que expõe resultados parciais de minha pesquisa de doutorado, fruto das preocupações de um professor de inglês interessado no caleidoscópio sistêmico de variáveis envolvidas no complexo processo de ensino/aprendizagem em sala de aula. A certeza da importância de uma teorização consistente e crítica para a escolha de práticas de pesquisa que sejam sensíveis às diferenças e às variações individuais e contextuais e que evidenciem a mutualidade entre teoria e prática é o que me encoraja a desenvolvê-lo. Interessamme, sobretudo, teorias que configuram a cognição e a linguagem como fenômenos que são dependentes da nossa dinâmica biológica e sociocultural, e que simultaneamente tanto são especificados por essas dinâmicas quanto as especificam, num processo recursivo e contínuo. Essas propostas podem dar origem a diálogos fecundos no que concerne ao temário do ensino/aprendizagem de línguas. Ganhos sistemáticos podem ser obtidos se esse processo for configurado como um fenômeno observado no domínio das interações situadas dos seres humanos, de maneira dependente da nossa dinâmica biológica, em especial de nossas emoções, como especificadoras das dinâmicas relacionais, tanto interpessoais quanto com o meio físico.

Meu principal interesse é contribuir para a reflexão conceitual já estabelecida na área da Lingüística Aplicada ao Ensino/Aprendizagem de Línguas Estrangeiras, ao introduzir aí a Biologia do Conhecer (MATURANA, 1998, 2001), aliada à pesquisa narrativa (CLANDININ e CONNELLY, 2000). Essa articulação nos permite desenvolver aquilo que Johnson e Golombeck (2002, p. 4) chamaram de uma epistemologia da prática. Primeiramente, apresento a fundamentação teórica da 
pesquisa, em seguida uma breve exposição de minha pesquisa e discussão de seus resultados parciais e, por último, proponho algumas reflexões sobre o exposto.

\section{As Ciências Cognitivas e a Biologia do Conhecer}

É comum ouvirmos dizer que o processo de aprendizagem de uma língua envolve a captação, o processamento e o armazenamento de formas e significados. Falamos cotidianamente sobre a linguagem como se ela fosse uma substância (LAKOFF e JOHNSON, 1980, p. 410), algo da realidade que pode ser quebrado em pedaços e consumido por uma determinada faculdade mental ou cerebral. Essa concepção de ensino/aprendizagem como depósito gradual de substâncias numa mente, aliada à visão de linguagem como contêiner de conteúdos mentais (idéias) e da comunicação como transferência desses conteúdos através de um tubo (canal) entre nossas cabeças funda nossa maneira cotidiana de falar e teorizar sobre linguagem e cognição (REDDY 1979; MAGRO, 1999).

Na metade do século XX, com o advento das assim chamadas Ciências Cognitivas (GARDNER, 1994), áreas de pesquisa como a Lingüística Aplicada e as Neurociências foram se consolidando como campos de pesquisa autônomos. Nesses campos, a mente humana, a Neurobiologia e suas inter-relações com a aprendizagem e a linguagem passaram a ser construídas conceitualmente em termos do processamento e armazenamento de informações computacionais. Essa compreensão, aliada a pesquisas pautadas na física e no positivismo como modelos paradigmáticos do fazer científico, edificaram um modelo conceitual canônico para o ensino e a aprendizagem de línguas marcado por: a) uma dissociação entre o fazer teórico e o fazer prático; b) a idealização de falantes, padrões lingüísticos, aprendizes, contextos e modelos de aprendizagem; c) a ênfase no ensino/aprendizagem como transmissão e processamento de informações; d) a marginalização de variáveis emocionais, históricas e políticas; d) o reducionismo e minimalismo explicativo (ARAGÃO, 2003). Nessa perspectiva, em conformidade com a tradição filosófica ocidental, a compreensão da cognição e da linguagem se dá pelo isolamento da razão, apontada como característica distintiva fundamental do ser humano. As emoções, 
nessa tradição, são tratadas como irrelevantes ou, quando reconhecidas, são consideradas secundárias e em geral perniciosas, com efeitos nocivos sobre a razão. Basta ver compêndios como os de Ellis (1994), Robinson (2001) e Lightbown e Spada (1999). É prática comum colocar as "variáveis" afetivas como secundárias às cognitivas e configurá-las de maneira limitada como "variáveis do aprendiz", a partir de arquiteturas conceituais dicotômicas e estáticas dos indivíduos. ${ }^{1}$

A Biologia do Conhecer, como se denomina o conjunto da obra de Humberto Maturana sobre o viver, orienta de outro modo nossa compreensão dos sistemas vivos, em geral, e dos seres humanos, em particular; dos processos neurofisiológicos que dão origem aos fenômenos emocionais e interacionais humanos; das relações entre os seres humanos e desses com o seu meio. A Biologia do Conhecer é um mecanismo explicativo dos sistemas vivos, caracterizados como sistemas dinâmicos operacionalmente fechados a instruções do meio, tratados como seres em constante transformação no viver e em permanente acoplamento estrutural com o meio. Com efeito, todo o viver é um conhecer, e todo o conhecer é um viver.

A Biologia do Conhecer nos permite abordar sistemicamente os processos de ensino/aprendizagem e, no que nos interessa aqui, o ensino/aprendizagem de inglês. A adoção desse modelo nos leva a: a) compreender cognição e linguagem como atividades mutuamente imbricadas, realizadas por agentes que co-constroem e coordenam ações de maneira recursiva em domínios consensuais operacionais e contextos relacionais, os quais envolvem a distinção de objetos e relações entre objetos, a distinção de si mesmo (autoconsciência) e de outras pessoas na convivência; b) dirigir nosso foco de observação para a dinâmica operacional histórica, situada e relacional de fenômenos distintos em reciprocidade, mútua constituição, afetação recíproca, sem colapsá-las e sobrepô-las; c) em conformidade com isso, apontar a reciprocidade de dois domínios não intersectantes e não redutíveis a fisiologia e o comportamento; d) entender que é o aluno, e não o

\footnotetext{
${ }^{1}$ A coletânea de Jane Arnold (1999) é uma exceção. O conjunto da obra evidencia os fatores afetivos, colocando-os em relação aos cognitivos. Entretanto, as arquiteturas conceituais dicotômicas e individualistas permanecem limitando uma visão dinâmica e sistêmica.
} 
meio, que especifica em suas interações o que pode ser ensinado/ aprendido/compreendido: cognição e comunicação não dependem "daquilo que se entrega", mas do que ocorre com aquele ou aquela que comumente se diz que "recebe"; e) em conseqüência, entender que a metáfora do computador / dos contêineres para a cognição e a linguagem perde seu valor explicativo corrente; f) apontar que os sistemas e os efeitos das perturbações interacionais são imprevisíveis e não têm relação com seu tamanho: uma pequena perturbação pode ter efeitos extensivos ou não ter o menor impacto ${ }^{2}$; g) reconhecer, em conformidade com isso, que tanto a variabilidade quanto a congruência e a estabilidade de padrões interacionais são observáveis, pertinentes e merecedoras de tratamento científico unificado; h) privilegiar descrições densas, que evidenciam a dinâmica das diversas variáveis que constituem o domínio sistêmico em operação, sobre as fórmulas dissecadas dos tratamentos formais.

\section{Emoções no ensino/aprendizagem de inglês}

Como falar aqui de emoções e compreender sua participação nesse processo? Maturana (1998, p.15-23) propõe compreendermos emoção como um fenômeno biológico relacional dos seres vivos, em especial, dos mamíferos. Do ponto de vista da Biologia, o que distinguimos como emoções são disposições corporais dinâmicas que especificam os domínios de ação, os tipos de condutas relacionais e interacionais possíveis num dado momento. Ao mudar de emoção, mudamos de domínio de ação, num fluir que Maturana chama de emocionar. Um domínio de ação é um domínio de condutas, comportamentos, posturas ou atitudes corporais que um observador distingue com uma emoção: é a emoção, e não a razão, que define a ação, embora em geral não

\footnotetext{
${ }^{2}$ VANLIER (2004), KRAMSCH (2002) e LANTOLF (2000) são articulações recentes de pensamento sistêmico no campo do ensino/aprendizagem de línguas. Entretanto, com o uso da teoria sociocultural de Vygotsky, da semiótica Peirciana, da teoria do caos/complexidade e da ecologia, há uma tendência de se privilegiar o papel das práticas sociais, obscurecendo, e até evitando, a reciprocidade fisiologia/interações e emoção/cognição, que na Biologia do Conhecer de Maturana é tão bem explorada.
} 
tenhamos dificuldade de justificar racionalmente nossas ações. Dessa forma, se se deseja saber qual a emoção, deve-se olhar a ação. Inversamente, se se quer saber qual a ação, basta olhar a emoção (MATURANA e BLOCK, 1996, p.114-115). No cotidiano sabemos muito bem disso: quando estamos numa determinada emoção, há coisas que podemos fazer e outras não, assim como há argumentos que aceitamos e outros não, dependendo da emoção. Lidamos cotidianamente com domínios nos quais só são possíveis certas ações e não outras, embora nem sempre nos damos conta disso. Portanto, a emoção define o que acontece na relação com os outros ou com nós mesmos, constituindo os espaços das dinâmicas relacionais em que nos movemos. Se olharmos o nosso próprio emocionar de maneira reflexiva, poderemos atuar coerentemente com ele ou mudar de domínio de ação, se assim o desejarmos e se isso for possível dentre o complexo de variáveis envolvidas (MATURANA e BLOCK, 1996, p. 117-118). Nesse espaço do saber sobre o saber, do dar-se conta de nossas ações e emoções, abrimos a possibilidade de uma atitude reflexiva responsável e ética, e de uma autoconsciência relacional. E essa abordagem é radicalmente diferente daquela que advoga o controle das emoções.

Sendo assim, o ponto de partida de um processo de ensino/ aprendizagem tem a ver, sobretudo, com um convite - e a aceitação mútua - para participarmos em conjunto de um espaço de convivência. Tudo depende dessa emoção, dessa possibilidade de nos movermos juntos de um lado para o outro, de estarmos num mundo de uma maneira ou de outra constituída no fluir de nossos encontros. A partir do emocionar é possível efetivarmos, numa convivência particular recorrente, uma transformação mútua que gere condutas adequadas, ou aqueles comportamentos que um observador, um professor, por exemplo, distingue como apropriado num contexto interacional por ele especificado. Nessa perspectiva, aprender uma língua estrangeira significa, sobretudo, estar disposto a conviver com outros numa rede de conversações, num linguajar constituído numa lógica processual, numa racionalidade e numa emoção distintas, com as quais estamos acostumados a conviver no nosso cotidiano. O ensino é um guiar, um conduzir numa convivência particular em que nos transformamos de maneira constante. Isso alude à compreensão da aprendizagem de uma língua não como a aquisição de uma entidade, mas como um espaço operacional de distinções 
recursivas e de coordenação de comportamentos, configurado consensualmente a partir das ações e emoções recorrentes que se realizam numa sala de aula e se estabilizam ao longo de um tempo recorrente de interações dessa natureza.

Portanto, ensino/aprendizagem é um processo de transformação no viver coletivo, cuja orientação é definida pela maneira segundo a qual um professor envolve os alunos no desenvolvimento de habilidades operacionais que compreende como necessárias para viver num domínio particular de existência - nesse caso, o de coordenação de ações recursivas e consensuais, ou o linguajar na língua especificada. Assim, tomo a aprendizagem e o ensino não como fenômenos apartados, nem sustentados por uma relação causal, mas como fenômenos processuais inter-relacionados de múltiplas e complexas maneiras. Dessa forma, o fenômeno de nosso interesse envolve um sistema de elementos processuais dinâmicos, relacionais, interativos e consensuais históricos, constituídos por uma ampla gama de componentes socioculturais, políticos e emocionais. Isso implica conceber a sala de aula como um espaço relacional multifacetado, um contexto co-constituído por alunos e professor no fluir de suas interações.

\section{São as histórias que nos dizem mais: emoção, reflexão e experiência narrativa}

Essa compreensão da dinâmica histórica e situada do viver humano, no meio com outros, pode ser articulada à pesquisa narrativa desenvolvida por Jean Clandinin e Michael Connelly (2000), e ao conceito de descrição densa (GEERTZ, 1973), com conseqüências frutuosas. Em conformidade com a Biologia do Conhecer, a pesquisa narrativa argumenta que: a) a qualidade da experiência humana é o foco principal de investigação; b) as vidas humanas são tecidas por um processo histórico, situado, multifacetado e complexo; c) o conhecimento é fruto do compartilhamento mútuo e dialógico com outros num espaço particular de convivência; d) o ato de narrar, que envolve o entrelaçamento de emoção e razão no linguajar reflexivo, provoca uma transformação na maneira como a pessoa compreende a si própria e aos outros envolvidos em sua história; e) a pessoa advoga por um 
imbricamento entre o narrar, o conscientizar e o agir; e) em conseqüência, a historicidade narrativa se constitui como um agente perturbador de atitudes reflexivas, que pode produzir um agente consciente, o qual se desloca de um círculo fechado de ação sem reflexão e passa a ser movido de seus desejos e escolhas.

Clandinin e Connelly (2000) apontam que nossas identidades acadêmicas são construídas por histórias pessoais e profissionais e as histórias dos outros constituem nosso meio de experiências, de modo que o coletivo e o pessoal são fios que produzem uma mesma imbricada teia. Somos indivíduos na coletividade, como sugere a Biologia do Conhecer de Maturana. Clandinin e Connelly enfatizam que vivenciamos os nossos encontros e interações cotidianas como histórias compostas de narrativas diversificadas. Tomando o conceito de experiência e continuidade de John Dewey, a pesquisa narrativa chama a atenção para a relação entre as variáveis históricas. Todo presente tem um passado e uma possibilidade de história futura enraizada nesse espaço prévio. Esse modo de caracterizar nossa experiência projeta importante conceituação sobre a construção da pesquisa de campo que é, sem dúvida, de grande valia para a compreensão qualitativa de nossas experiências profissionais cotidianas.

Ao narrar histórias, memórias e eventos marcantes em sua vida, um aluno pode se conscientizar e agir coerentemente com seu emocionar. Como sugere Telles (2004, p. 80-81), no processo de recontar seu viver, os alunos podem reavaliar histórias antigas e partir para outras histórias com as quais desejam viver. Johnson e Golombeck (2000, p.3-5) afirmam, em conformidade com Telles e embasados na obra de Dewey, que na atividade narrativa há um processo de autoconhecimento no qual se pode questionar sua própria conduta em relação ao seu meio contextual e agir em conexão com a compreensão de sua experiência e desejo. Durante esta atividade o aluno passa a ser autor de sua própria história, ao compreendê-la em sua forma processual e inter-relacionada a outros eventos marcantes (cf. p. ex. TELLES, 2002).

O conceito de descrições densas, proposto por Geertz (1973), busca um tipo de esforço intelectual que envolve a observação mais completa possível e a interpretação cuidadosa de culturas particulares. Essa atividade é realizada na socialização e na participação dialógica 
do pesquisador no conviver com um determinado grupo de pessoas. Nesse processo de investigação, o pesquisador procura estabelecer conexões, padrões, rupturas e significados das ações no emaranhado sistêmico das relações experenciais humanas. Isso se dá com a coleta de documentos variados de campo, que podem apresentar diferentes perspectivas dos participantes e do pesquisador, processo conhecido como triangulação. Com base nesses documentos, o pesquisador pode estabelecer um intercruzamento de dados na compreensão multicomponencial do processo de transformação na convivência.

\section{Articulando emoção, cognição e reflexão na sala de aula}

A presente pesquisa, cujos resultados preliminares trago à reflexão, foi realizada numa sala de aula de língua inglesa no curso de graduação em Letras de uma universidade federal. Selecionei para realizá-la uma disciplina na qual se dá o primeiro contato dos alunos calouros com o ensino/aprendizagem de inglês. Nessa faculdade, o curso de graduação em língua inglesa se inicia no nível intermediário. A exigência do nível intermediário para o início dessa experiência para alunos interessados na habilitação em língua inglesa é parte constitutiva do cenário emocional da pesquisa.

O universo da pesquisa envolveu dez participantes. O que vou expor aqui, no entanto, são minhas observações no contato com apenas uma aluna, que adotou o pseudônimo de Júlia. Em conformidade com os marcos teóricos adotados, a pesquisa de campo consistiu de uma diversidade de atividades (cf. p. ex. MICCOLI, 1997), nas quais os seguintes documentos de campo foram produzidos: a) uma narrativa autobiográfica escrita; b) três transcrições de entrevistas semiestruturadas que somadas representam 4 horas; c) filmagens de 20 aulas; d) notas de campo; e) notas realizadas durante conversas informais com a participante; f) uma colagem; g) respostas a um questionário final; h) um diário. A narrativa autobiográfica escrita pelos participantes versou sobre suas histórias de aprendizagem de inglês. A colagem, um interessante instrumento no qual, através de desenhos próprios ou imagens retiradas de revistas, o participante conta sua história, indica como se sente, sem as limitações da linguagem. Os alunos, 
em geral, narram seu contato com a língua inglesa como uma empreitada muito difícil, desafiadora, exigente e, muitas vezes, assustadora. Júlia descreve sua experência no excerto abaixo, em sua primeira entrevista:

$\mathrm{R}$ - Você disse também que no curso se cobra muito do aluno?

J - Acho que é a maneira como o inglês é colocado na faculdade, é como olha, o inglês é difícil, é um monstro e ele tem sete cabeças, se você não tem no seu currículo uma luta de bicho de sete cabeças, você não vai passar, entendeu, e sempre colocam o inglês assim, como esse "big monster" e está todo mundo querendo aprender, mas o professor está num patamar superior e o inglês é uma língua difícil.

Essa metáfora, "lutar com o bicho de sete cabeças", modula de maneira central as condutas relacionais de Júlia na faculdade. Ela está imersa em lutas com esse bicho e pretende vencê-lo a qualquer custo. Esse desejo, essa disposição relacional de querer vencer a luta contra o bicho de sete cabeças pode explicar, em parte, a perseverança de Júlia quanto ao seu aprendizado e ao seu sucesso final na disciplina.

No roteiro para a terceira e última etapa do processo de reflexão, a colagem, lia-se a seguinte orientação:

Numa folha, monte uma pequena história, um enredo, com palavras e imagens que descreva esta etapa de seu processo de aprendizagem de inglês na faculdade. Pense na sua história nesta disciplina e lembre-se de suas expectativas, faça uma reflexão.

Depois dessa atividade, fiz uma última entrevista com Júlia para esclarecer os sentidos das imagens que ela apresentou na colagem. Esta história narrada na última entrevista e desenhada como uma história em quadrinhos resume sua trajetória na disciplina:

J - Então aqui começa a minha estória, o que podemos ver de cara é que ele (o aluno - personagem da história) começa tristonho e termina feliz. Ele entra cabisbaixo e vai falando "ai que droga de aula de inglês" e sai pior ainda, com a língua para fora: "puxa vida, achava que sabia alguma coisa de inglês, eu sou um fracasso". E assim os dias se passaram e o aluno se sentia desvalorizado. Aí ele acorda cedo na cama dele para ir à aula e era um tédio e ele fala: "ai que droga, a professora vai ficar corrigindo exercícios e pensando que está ensinando, e eu fingindo que estou aprendendo." Mas o tempo foi passando, mas o tempo só não passa como amadurece e o aluno foi tomando conhecimento, se tornando consciente de que ele é 
capaz e que dá conta, independente do que os outros digam e (...) Aí ele vai saindo da aula de inglês, ele passa a se sentir grande e confiante, levanta os ombros e acredita em si e consegue vencer, pena que esta não seja a história de todos. Então eu acho assim, que no final, hoje estou me sentindo muito segura, muito mais segura do que, vamos supor, nossa primeira entrevista. Eu estou me sentindo assim nesse semestre, achei que entrei para baixo e estou saindo super para cima. Eu vi que o meu inglês caminhou e eu melhorei meu relacionamento com a professora, isso também melhorou porque eu falei o que quis falar. Teve hora que discordei e levantei a voz na sala de aula e falei com ela as coisas e enfrentei ela. Não tive medo dela e isso para mim foi bom e foi bom pra eu levantar minha bola, entendeu?

Dessa pequena história, gostaria de destacar: a) Júlia era aluna repetente; b) Júlia iniciou o curso com baixa auto-estima, constrangida, desacreditada, calada e decepcionada com a professora, consigo mesma e com o curso, mas terminou com auto-estima, confiante em si mesma e com uma boa relação com a professora; c) Júlia conseguiu vencer o bicho de sete cabeças, perceber que é capaz e que a professora deseja ajudá-la, e não fazê-la fracassar; d) acredito que o processo narrativo-reflexivo ajudou Júlia a desenvolver a autoconsciência de que precisava para deixar para trás algumas experiências decepcionantes, confiar em si mesma e participar das aulas em pé de igualdade com os colegas e com a professora. Em outras palavras, Júlia precisava mudar seu domínio de ações. À medida que deixa de se preocupar com o que outro está pensando a seu respeito, há uma mudança radical no que é capaz de realizar em sala de aula.

Júlia trabalha, há pouco mais de um ano, numa escola infantil. Acredita que o objetivo de ensinar inglês para as crianças é semear o amor pelo aprendizado da língua inglesa. Sobre sua história pessoal e condição sócio-econômica, conta, em sua narrativa autobiográfica redigida no início do curso, que:

J - Venho de família simples, que sempre batalhou e estudei sempre em escolas públicas, cujo ensino não era de muita qualidade. Iniciei o meu contato com a língua inglesa ouvindo e traduzindo músicas da Madona aos 12 anos. Sempre pedi a meus pais que me matriculassem em um cursinho de inglês, mas realmente não tínhamos dinheiro e teria que aprender sozinha. 
Esse aspecto de sua história auxilia a explicar sua tenacidade, persistência, determinação e o enorme desejo de domar o "bicho de sete cabeças". No início de seu diário reflexivo, diz: "É claro que não vou desistir. É por isso que estou aqui hoje. Vou repetir quantas vezes forem necessárias (...) a coragem de nunca abandonar a nau é para mim o que há de mais valioso". Numa conversa informal que tivemos na cantina, perguntei como encarava o processo de aprendizagem naquele semestre. Respondeu que estava subindo uma montanha e que tinha que deixar alguns pesos para trás. De fato, o que Júlia percebeu ao longo do semestre, à medida que avançávamos em nossas reflexões, era que deveria deixar para trás e superar as experiências negativas que funcionavam como um bloqueio, limitando o seu desenvolvimento, sobretudo sua fluência oral. Além disso, precisava superar um pensamento depreciativo associado a um sistemático discurso negativo de fracasso e reprovação de si mesma. Júlia veio estudar Letras com o desejo de se tornar professora de inglês. Como sua situação socioeconômica a impedia de freqüentar um curso de inglês, tinha que aprender sozinha, conforme relata:

J - Não tinha como praticar a língua, pois no colégio as aulas eram ministradas em português. Comecei a escrever pequenas frases em inglês nas cartas que escrevia a um amigo que sempre teve um bom nível na língua. Como era iniciante, errava muito. Ele, como era adolescente, também me ridicularizava na frente de todos os nossos amigos, ao invés de me corrigir à parte. O que poderia ter sido a alavanca para o crescimento tornou-se a areia movediça que me fez sentir inferior a todos. Sentia-me incapaz de conseguir aprender uma segunda língua. Cresci com este sentimento de inferioridade, até chegar na faculdade.

A interação com o colega marcou Júlia de uma forma profunda e, posso dizer, é um dos marcos históricos cuja identificação Clandinin e Connelly (2000) consideram importante. De alguma maneira, esse sentimento de inferioridade, a auto-avaliação negativa e a baixa autoestima acompanharam Júlia durante quase todo o seu processo de aprendizagem até então. O medo, o constrangimento e a insegurança que relata em suas narrativas limitavam seu campo de ação na sala de aula. Em nossas conversas e entrevistas, sempre procurava refletir sobre essas emoções. 
No início do curso, Júlia era uma aluna calada e pouco participativa. Sentava na frente junto a alguns colegas também repetentes, mas não participava das atividades propostas pela professora. Eu sentia que ela estava sempre em algum outro lugar. Para ela, falar inglês na sala é como "pisar em ovos" ou como "se o ar tivesse facas". Essas metáforas nos auxiliam a compreender a dinâmica relacional de medo, cautela e desconfiança que levavam Júlia a participar pouco das atividades que envolviam o uso de inglês em sala de aula. Numa conversa informal que tivemos no final de uma aula, procurei abordar a questão de sua participação nas tarefas da sala de aula. No primeiro mês, observei que não perguntava, não interagia com outros na turma. Indaguei-a sobre essa situação recorrente e esta foi sua resposta: "quando converso inglês sinto que o outro está sempre me corrigindo, é como se o ar tivesse facas, estou sempre pisando em ovos, parece que estão me julgando, avaliando, criticando."

Essa sensação de estar permanentemente exposto e julgado (cf. p. ex. MICCOLI, 1997) é um traço recorrente não só de Júlia, mas também dos outros participantes da pesquisa. Todos, com exceção de uma participante, relatam desse modo seu extremo desconforto ao falar inglês em público. Em linhas gerais, há um sentimento de bloqueio limitador da ação, de extrema preocupação consigo mesmo e com a opinião alheia, acompanhado de um sentimento de observação julgadora contínua de que os demais presentes podem estar criticando sua conduta. Acompanha esse desconforto o medo de errar, medo de fazer perguntas, medo do que o outro pode estar pensando sobre você, o constrangimento, a vergonha e o retraimento interacional.

À medida que construía sua autoconfiança, a sensação de pisar em ovos foi se dissipando. Porém, até a última entrevista e nas últimas aulas, percebia que Júlia ainda oscilava em sua insegurança. Entretanto, depois da nossa segunda entrevista, observei uma mudança significativa. Na entrevista decidi enfatizar a sua preocupação com a opinião e a avaliação dos outros, esse sentimento de pisar em ovos na sala e a sensação de facas no ar. Num determinado momento, introduzi esse tema em nossa reflexão, ao qual retornei sistematicamente:

$\mathrm{R}$ - Você faz perguntas, né?

$\mathrm{J}$ - Faço.

$\mathrm{R}$ - O que te leva a fazer uma pergunta? 
$\mathrm{J}$ - Do que surgir na hora.

$\mathrm{R}$ - E você tem algum medo e receio de fazer pergunta?

J - Agora não (risos), porque agora acho que eu escrachei...(risos)

R - (risos) Por que agora não, Júlia?

$\mathrm{J}$ - Estou mais segura, Rodrigo, graças a Deus, estou mais segura nesse curso. Acho que estou melhorando no inglês. Eu acho que tenho capacidade (...)

Procurei enfatizar essa questão na tentativa de torná-la mais consciente. No trecho seguinte, pergunto como está "o alpinista" na aprendizagem de inglês, com o intuito de fazê-la perceber que poderia superar suas dificuldades e a sensação de desconforto:

R - Qual que é o problema do inglês, Júlia?

$\mathrm{J}$ - Acho que o problema do inglês, no semestre passado principalmente, foi esse, foi um pouco do medo, desse medo de me achar incapaz, o medo de não dar conta, né?

$\mathrm{R}$ - E como está o alpinista, Júlia?

J - (risos) Acho que ele está subindo legal, Rodrigo, acho que ele está usando as ferramentas que devia, acho que ele está subindo com mais confiança.

$\mathrm{R}$ - Qual é a origem desse medo, Júlia?

J - É a crítica, o medo da crítica para mim, a Nati (uma colega de sala), por exemplo, não tem esse medo.

$\mathrm{R}$ - Medo do olho do outro?

J - É... por que que tenho esse medo do olho?

$\mathrm{R}$ - Você tem alguma sugestão para superar isso?

J - Yoga (risos). Estou brincando, não sei, mas alguma coisa desse tipo.

$\mathrm{R}$ - De criar autoconfiança?

$\mathrm{J}$ - De trabalhar isso com você, com o seu pessoal.

$\mathrm{R}$ - Então se você se preocupar menos com o olho dele, com os seus erros...

J - Mas eu preocupo demais, sabe, para falar esse pouquinho de inglês, algumas frases. Aí já vi que na minha cabeça aqui fervendo, será que estou falando isso certo? Será que o Rodrigo está corrigindo minha pronúncia? Será que eu tenho algum erro?

$\mathrm{R}$ - Está passando da hora, vamos para a aula?

J - Vamos, está na hora. 
Júlia foi para a sala, enquanto desci até a cantina. Quando voltei, Júlia estava sentada junto com os colegas que mais participavam oralmente da aula. Acompanhei quem detinha o turno durante uma atividade de resolução de problemas. Nessa atividade, havia um crime a ser solucionado e, a partir dos hóspedes da casa, os alunos tinham que provar quem era o culpado. Júlia manteve o turno por trechos longos e entrou num embate conversacional com a aluna-participante Nati, a colega que Júlia achava ser superior a ela. Num determinado momento, a conversa começou a circular de maneira aberta na sala, de forma que poucas pessoas tomavam o turno conversacional. Mas nesse dia Júlia falou muito mais do que de costume. Alguma mudança radical ocorreu no que Júlia podia fazer na sala. Sua emoção, seu domínio de ação, sua atitude naquele meio relacional haviam se transformado. Era como se, durante aquela aula, tivesse deixado o espaço de sala de aula no qual pisava em ovos e driblava as facas que estavam no ar. Sua emoção ou, para relembrarmos o modo como estou aqui definindo esse fenômeno, sua disposição corporal para ação havia mudado, assim como mudou o seu ambiente interacional. Foi como se uma outra dinâmica tivesse entrado em cena. Observei que essa mudança se estendeu às aulas seguintes. Júlia descreveu em sua colagem e na entrevista final que falar inglês com fluência seria como "vestir a capa de um rei”. Naquele dia, Júlia colocou sua coroa de rainha. Falou com fluência e desenvoltura durante toda a aula. Fiquei atônito. Selecionei o trecho final de nossa última entrevista, quando procurei explorar os efeitos de nossa concatenação de reflexões acerca de sua experiência na aprendizagem de inglês, para reproduzi-lo aqui, na íntegra:

$\mathrm{R}$ - Como avalia que esse processo de reflexão pode estar auxiliando nessa consciência de que você já sabe alguns caminhos a percorrer?

$\mathrm{J}$ - Eu acho que a sua presença na sala me dava segurança. Eu pensava assim: tem um doutorando na sala e esse trabalho que a gente fez, me fez pensar, me fez refletir mesmo sobre a minha capacidade, sobre a minha falta de confiança em mim mesma. Vi que não é por aí, que eu sei que alguma coisa eu sei, tanto que estou aqui. Minhas notas nesse semestre foram boas, mas ainda tem muito para aprender, mas estou muito mais confiante. Fui vendo que o professor da faculdade não é o rei e talvez eu também não vou ser nenhuma rainha para ninguém. Vai ver que vou ser essa rainha para mim, mas eu posso não ser para as outras pessoas que vão chegar e vão me 
contestar. Espera aí, não é assim que pronuncia, não é assim que se fala. Não, isso está errado! Mas eu vi que posso contestar também, não preciso me sentir inferior e nem me curvar para a professora de inglês da faculdade. Eu vi isso esse semestre na faculdade. Esse processo que a gente fez de reflexão nesse semestre me fez ver isso, que posso refletir e que posso discutir, que posso argumentar e me fez crescer. Isso me fez crescer muito. Hoje estou me sentindo bem melhor com relação ao inglês, bem segura de mim mesmo.

$\mathrm{R}$ - É, acho que assisti isso, Júlia, aí, depois da segunda entrevista.

$\mathrm{J}$ - Me sinto muito mais segura, o pisar em ovos pode até continuar, mas agora eu sei onde é que estou pisando, sabe, sei onde estão os ovos.

R - É, e acho que mudou. Eu sinto que isso mudou na documentação filmada e observei na sala, eu vejo que mudou, talvez, como você mesma falou, tenham outras coisas também. Sua vida pessoal está melhor, né?

$\mathrm{J}$ - É, pode isso ser também (risos).

$\mathrm{R}$ - Né (risos).

J - A segurança vem das coisas que você me fala, o fato de você falar essas coisas pra mim, me fez caminhar melhor, que eu podia dar conta, só que não conseguia enxergar isso, que se eu posso fazer isso assim é assumir a capa do rei e aí tenho de prestar contas da minha realeza. Se diz que é rei, cadê? A responsabilidade fica maior, sabe?

\section{Reflexões finais}

Júlia mudou. Eu mudei. Júlia vive hoje um outro domínio de ação, uma outra emoção, diferente daquela na qual estava no início de nossa conversação. Acredito que hoje vivemos uma outra maneira de nos colocarmos na relação com os outros. Nesse conversar, nesse dar voltas em conjunto, entrelaçando o emocionar com o conversar (MATURANA, 1998, p.34), concatenando reflexões de autoconsciência em conjunto, nos transformamos sempre de uma maneira inevitável, embora nem sempre perceptível. Maturana e Block (1996) apontam que a reflexão é um ato de emoção no desapego, no qual se sai de uma certeza, de uma condição que nos cega e abre-se a mão para ver o que antes não víamos. O saber e a certeza negam a reflexão, pois não se reflete sobre 
o que se tem como certo. Na reflexão admitimos que não agimos mais numa certeza, e aí há um deslocamento. Quando refletimos, vivemos uma mudança na corporalidade e uma mudança na conduta, e aí podemos fazer coisas que antes não podíamos. A história de vida de Júlia e nossas conversações haviam modulado uma nova conduta, assim como as próprias emoções vividas na sala modificaram sua vida pessoal e acadêmica, numa dialogia constante. Nosso conversar, nosso recontar participaran desta dança emocional e racional, especificando e modulando domínios possíveis nas concatenações de reflexões que desenvolvemos em conjunto.

Podemos promover espaços de reflexão em conjunto de várias formas. O primeiro passo é conhecer um pouco das trajetórias de aprendizagem entre alunos e professor. Isso pode ser iniciado através da escrita de uma narrativa autobiográfica sobre a história pessoal e escolar do aluno e do professor. O objetivo central é relatar as experiências prévias com a língua inglesa, os prazeres e desprazeres na aprendizagem da língua, assim como descrever crenças e estratégias de aprendizagem. Os alunos e o professor podem compartilhar suas histórias, em pares ou em pequenos grupos. Pode ser feita também uma colagem descritiva, usando desenhos ou figuras que encorajem a reflexão sobre questões como o sentimento predominante nas aulas, a sensação de falar inglês na sala, como é ou como poderia ser a sensação de falar inglês com fluência, as estratégias utilizadas para otimizar a aprendizagem, e, se se pretende ser professor, que imagem pode simbolizar esse papel. A colagem pode ser um artifício produtivo para quem tem dificuldade de discorrer verbalmente sobre seus sentimentos e emoções. Realizada essa atividade, o professor pode entrevistar os alunos para explorar pontos da colagem e da narrativa. O professor pode ainda organizar entrevistas entre os alunos, levandoos a ler as narrativas dos colegas e a montar um questionário para aprofundar a reflexão. Pode-se manter também um diário que relate as emoções vividas na sala ou uma troca de cartas entre os alunos e o professor. É necessário orientá-los para o foco reflexivo de sua escrita, para que não fiquem apenas no nível descritivo. Conversas em pares ou em grupo sobre emoções envolvidas na aprendizagem também podem ser fomentadas. Os alunos podem gravar as apresentações orais uns dos outros, ou situações de interação oral, e depois refletir sobre 
as mesmas em sessões de auto-observação reflexiva com o professor ou aluno com aluno. De fato, não há uma receita geral.

Antes de entrar na sala como pesquisador e escutar as histórias e experiências de Júlia (e dos outros participantes), não esperava que as ações de nossos alunos pudessem ser balizadas de tal maneira por nossas emoções, nossa auto-observação/consciência e nossas histórias de vida. Foi marcante compreender que falar inglês na sala de aula envolve uma gama de variáveis muito maior que a combinação de gramática e vocabulário na interação comunicativa. Comunicar em inglês na sala envolve questões como as histórias de interações prévias do aluno com a língua e todo o seu entorno de significados pessoais, emocionais, identitários, de atribuição de poder na sala, e as várias faces do medo, como medo do próprio julgamento e dos outros ali presentes, constrangimento relacional, vergonha, auto-estima, confiança e insegurança, ansiedade, preocupação e culpa.

Atualmente, compreendo de maneira sistêmica que quanto maior a empatia entre professor e aluno melhores são os resultados. Há uma distância entre o mundo do aluno e o do professor na sala de aula. Esses mundos envolvem distintas crenças que podem gerar conflitos pela falta de um co-emocionar mais harmônico e congruente. No entanto, uma maneira de encurtarmos as distâncias é participarmos do mundo deles, de suas conversações, de suas histórias, e convidá-los a participarem das nossas.

Precisamos dar vozes a todos na sala de aula, pois é conversando que podemos nos entender melhor, por conhecermos as semelhanças e diferenças entre nossas histórias e emocionares. Como apontei, temos a nossa disposição diversas maneiras de fomentar essa atitude reflexiva na sala: uso de diários, narrativas, autobiografias, discussões em grupo, leituras coletivas de narrativas, filmagem e auto-observação de cenas de sala de aula em que estamos expostos, colagens, entre outras. Basta estarmos dispostos a entrar nesse emaranhado inter-relacional sistêmico e também admitir, como a própria Júlia apontou no questionário final, que "A reflexão é para todos, mas nem todos são para a reflexão". Claro, as disposições para entrar em espaços de reflexão e transformação são diversificadas.

Mais um ponto relacionado ao bailar da emoção e da cognição: a transformação na convivência envolve a aceitação e a disposição 
mútua para que os envolvidos possam participar de um domínio em conjunto, a reflexão, a tomada de consciência, o desejo de mudança e a possibilidade de transformação na contingência. Precisamos compreender a constituição desses domínios de ação na sala e como a reflexão, a cognição e a emoção caminham em conjunto. Os desafios são muitos, mas a viagem é compensadora.

\section{Referências Bibliográficas}

ARAGÃO, R. Reflexões Epistemológicas sobre o Campo de Ensino e Aprendizagem de Segunda Lingua e sua Relevância para a Prática de Sala de Aula. 2003. Dissertação (Mestrado em Lingüística) - Faculdade de Letras, UFMG, Belo Horizonte. (Inédita)

CLANDININ, J.; CONNELLY, M. Narrative Inquiry: Experience and Story in Qualitative Research. San Francisco: Jossey Bass Publishers, 2000. p.4-26.

ELLIS, R. The Study of Second Language Acquisition. Oxford: Oxford University Press, 1994.

GARDNER, H. A Nova Ciência da Mente - Uma história da revolução cognitiva. São Paulo: Edusp, 1995.

GEERTZ, C. The Interpretation of Cultures. New York: Basic Books, 1973.

JOHNSON, K.; GOLOMBEK, P. (Ed.). Teacher's Narrative Inquiry as Professional Development. New York: Cambridge University Press, 2002. p.1-13.

LAKOFF, G.; JOHNSON, M.; Metaphors We Live By. Chicago: University of Chicago Press, 1980. p. 2-10.

KRAMSCH, C. Language Acquisition and Language Socialization. Ecological Perspectives. London: Continuum, 2002.

LANTOLF, J. (Ed.). Sociocultural Theory and Second Language Learning. Oxford: Oxford University Press, 2000

LIGHTBOWN, P. M; SPADA, P. How Languages are Learned. Oxford: Oxford University Press, 1999.

MAGRO, C. Linguajando o Linguajar - da Biologia à Linguagem. Instituto de Estudos da Linguagem. Campinas: Universidade Estadual de Campinas, 1999. 
MATURANA, H. Biologia da Autoconsciência. In: MAGRO, C.; GRACIANO, M.; VAZ, N. (Org.). A Ontologia da Realidade. Belo Horizonte: Ed. UFMG, 1997. p.211-241.

MATURANA, H. Emoções e linguagem na educação e na política. Belo Horizonte: Ed. UFMG, 1998.

MATURANA, H. Biologia do Conhecer e Epistemologia. In: MAGRO, C.; PAREDES,V. (Org.). Cognição, Ciência e Vida Cotidiana. Belo Horizonte: Ed.UFMG, 2001. p. 19-124.

MATURANA, H.; BLOCK, S. Biologia del Emocionar y Alba Emoting. Santiago del Chile: Dolmen Ediciones, 1996.

MICCOLI, L. Learning English as a Foreign Language in Brazil: a Joint Investigation of Learner's Experiences in a University Classroom. 1997. Tese (Doutorado) - University of Toronto, Toronto. (Inédita)

RAJAGOPALAN, K. Por uma Lingüística Crítica: linguagem, identidade e a questão ética. São Paulo: Parábola Editorial, 2003. p. 77-81.

REDDY, M. The Conduit Metaphor: a case of frame conflict in our language about language. In: ORTONY, A. (Ed.). Metaphor and Thought. Cambridge: Cambridge University Press, 1979. p. 164-201.

ROBINSON, P. Cognition and Second Language Instruction. Cambridge: Cambridge University Press, 2001.

TELLES, J. "É pesquisa, é? Ah, não quero não bem!" Sobre pesquisa acadêmica e sua relação com a prática do professor de línguas. Linguagem e Ensino, v. 5, n. 2, p. 91-116, 2002.

TELLES, J. Reflexão e identidade profissional do professor de LE: Que histórias contam os futuros professores? Revista Brasileira de Lingüistica Aplicada, v. 4, n. 2, p. 57-83, 2004.

VANLIER, L. The Ecology and Semiotics of Language Learning. A Sociocultural Perspective. Norwell: Kluwer Academic Publishers, 2004. 